\title{
Editorial from Journal Editors
}

\section{Patient Care, Professionalism and Relations with Industry}

\author{
Richard A. Brand MD, Joseph A. Buckwalter MD, Timothy M. Wright PhD, \\ S. Terry Canale MD, William P. Cooney III MD, Robert D'Ambrosia MD, \\ Frank J. Frassica MD, William A. Grana MD, MPH, James D. Heckman MD, \\ Robert N. Hensinger MD, George H. Thompson MD, L. Andrew Koman MD, \\ Peter D. McCann MD, Gary G. Poehling MD, James H. Lubowitz MD, \\ David Thordarson MD, Robert J. Neviaser MD
}

(C) The American Academy of Orthopaedic Surgeons 2008

Patient care is the primary focus of the orthopaedic profession. The enhancement of patient care has required and will continue to require orthopaedic surgeons to collaborate productively with industry to develop new medical technology and techniques that improve patient care. The relationship between orthopaedic surgeons and industry is of critical importance to the shared ultimate goal of improving patient care. Orthopaedic surgeons are well

\footnotetext{
Adapted and reprinted with permission from the American Academy of Orthopaedic Surgeons, Rosemont, IL.

Editor's note: The editors of numerous journals in orthopaedics are running this or a similar editorial. As a group we feel the issue of transparency with patients about orthopaedic surgeons' relationships with industry is complex and important, and every orthopaedic surgeon should be familiar with the new AAOS SOPs on Orthopaedist-Industry Conflicts of Interest. They may be found at www.aaos.org/industryrelationships. The article is reproduced with permission of the AAOS.
}

\section{R. A. Brand ( $\square)$}

Clinical Orthopaedics and Related Research

\section{J. A. Buckwalter, T. M. Wright}

Journal of Orthopaedic Research

S. Terry Canale

AAOS Now

W. P. Cooney III

Journal of the American Academy of Orthopaedic Surgeons

R. D'Ambrosia

Orthopedics

F. J. Frassica

Orthopedics Hyperguide

W. A. Grana

Orthopaedic Knowledge Online qualified to provide innovative ideas and feedback to industry, conduct research trials, serve on scientific advisory boards, and serve as faculty to teach the uses of new technology. The relationship between orthopaedic surgeons and industry is important and necessary, but it must be scrutinized carefully to avoid the pitfalls of real or perceived conflicts of interest that ultimately could affect patient care.

In late September, four orthopaedic manufacturing companies entered into Deferred Prosecution Agreements, agreeing to pay civil settlements amounting to a total of \$311 million. In addition, one orthopaedic company entered into a Non-Prosecution Agreement. All will be subject to oversight by a federal monitor appointed by the U.S. Department of Justice for 18 months. The companies did not admit any wrongdoing, plead guilty to any criminal charges or pay any criminal fines as part of the settlement. The federal government, through the U.S. Attorney's

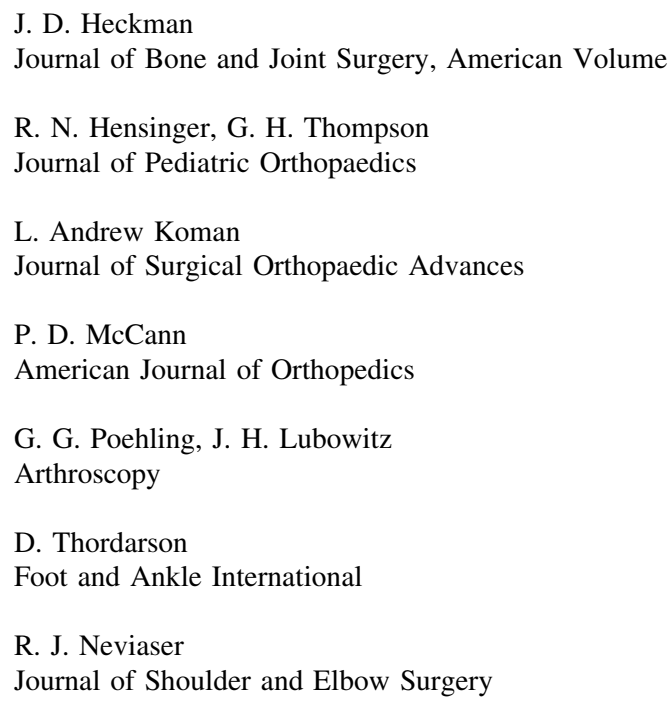


Office in New Jersey, has agreed not to pursue any criminal charges against the companies if they comply with the Agreements. Clearly, a spotlight has been shone on companies and orthopaedic surgeons alike.

Earlier in the year, the Fellowship of the American Association of Orthopaedic Surgeons (AAOS) adopted Standards of Professionalism on Orthopaedist-Industry Conflicts of Interest (SOPs). Of those Fellows voting (5242), approximately $96 \%$ voted to adopt these SOPs. These SOPs establish mandatory, minimum levels of acceptable conduct for Fellows and Members of AAOS who engage in relationships with industry. They focus on how orthopaedic surgeons serve the best interests of the patient and the profession while participating in academic or commercial ventures. There are 17 standards* relating to industry; it is in every surgeon's best interest to be familiar with all 17 . The SOPs address such topics as consulting agreements, industry-sponsored events, inappropriate financial arrangements, CME courses, and gifts from industry. Each of these standards addresses a real or perceived conflict that has the potential to influence decisions about patient care and to do so in a way that is not in the best interests of the patient or ultimately may increase risks for or even cause injury to the patient.

The AAOS SOPs emphasize the patient-physician relationship. The mandatory standards call for orthopaedic surgeons to tell patients about their relationships with industry that create real or perceived conflicts of interest and to resolve these conflicts in the best interest of the patient. Some orthopaedic surgeons may find that the SOPs validate their existing practices. Other orthopaedic surgeons may wish to revise how their practices address possible conflicts.

AAOS will begin enforcing these SOPs for acts occurring on or after January 1, 2008. As with the other AAOS SOPs, allegations that a Fellow has violated any of the SOPs on Orthopaedist-Industry Conflicts of Interest may result in a formal grievance under the AAOS Professional Compliance Program. Orthopaedic surgeons found in violation of the SOPs may be censured, suspended, or expelled from the AAOS.

We encourage each of you to become familiar with the SOPs on Orthopaedist-Industry Conflicts of Interest and to discuss them with your colleagues. Avoiding the pitfalls of real or perceived conflicts of interest with industry enhances your personal professionalism. Maintaining productive relationships with industry that advance patient care enhances the entire orthopaedic profession.

* Mandatory standards [excerpted from the complete Standards of Professionalism (SOPs) on OrthopaedistIndustry Conflicts of Interest]:
1. An orthopaedic surgeon shall, while caring for and treating a patient, regard his or her responsibility to the patient as paramount.

2. An orthopaedic surgeon shall prescribe drugs, devices, and other treatments primarily on the basis of medical considerations and patient needs, regardless of any direct or indirect interests in or benefit from industry.

3. An orthopaedic surgeon convicted of violating federal or state conflict of interest laws or regulations shall be subject to discipline under the AAOS Professional Compliance Program.

4. An orthopaedic surgeon shall, when treating a patient, resolve conflicts of interest in accordance with the best interest of the patient, respecting a patient's autonomy to make health care decisions.

5. An orthopaedic surgeon shall notify the patient of his or her intention to withdraw from the patientphysician relationship, in a manner consistent with state law, if a conflict of interest cannot be resolved in the best interest of the patient.

6. An orthopaedic surgeon shall decline subsidies or other financial support from industry, except that an orthopaedic surgeon may accept gifts having a fair market value of less than $\$ 100$, medical textbooks, or patient educational materials.

7. An orthopaedic surgeon who has influence in selecting a particular product or service for an entity shall disclose any relationship with industry to colleagues, the institution and other affected entities.

8. An orthopaedic surgeon shall disclose to the patient any financial arrangements with industry that relate to the patient's treatment, including the receipt of inventor royalties, stock options or paid consulting arrangements with industry.

9. An orthopaedic surgeon shall accept no direct financial inducements from industry for utilizing a particular implant or for switching from one manufacturer's product to another.

10. An orthopaedic surgeon shall enter into consulting agreements with industry only when such arrangements are established in advance and in writing to include evidence of the following:

- Documentation of an actual need for the service;

- Proof that the service was provided;

- Evidence that physician reimbursement for consulting services is consistent with fair market value; and

- Not based on the volume or value of business he or she generates. 
11. An orthopaedic surgeon shall participate in or consult at only those meetings that are conducted in clinical, educational, or conference settings conducive to the effective exchange of information.

12. An orthopaedic surgeon shall accept no financial support from industry to attend industry-related social functions where there is no educational element.

13. An orthopaedic surgeon who is attending a CME event shall accept no industry financial support for attendance at a CME event. Residents and orthopaedists-in-training may accept an industry grant to attend a CME event if they are selected by their training institution or CME sponsor and the payment is made by the training program or CME sponsor. Bona fide faculty members at a CME event may accept industry-supported reasonable honoraria, travel expenses, lodging and meals from the conference sponsors.

14. An orthopaedic surgeon, when attending an industrysponsored non-CME educational event, shall accept only tuition, travel and modest hospitality, including meals and receptions; the time and focus of the event must be for education or training.

15. An orthopaedic surgeon, when attending an industrysponsored non-CME educational event, shall accept no financial support for meals, hospitality, travel, or other expenses for his or her guests or for any other person who does not have a bona fide professional interest in the information being shared at the meeting.

16. An orthopaedic surgeon, when reporting on clinical research or experience with a given procedure or device, shall disclose any financial interest in that procedure or device if he or she or any institution with which he or she is connected has received anything of value from its inventor or manufacturer.

17. An orthopaedic surgeon who is the principal investigator shall make his or her best efforts to ensure at the completion of the study that relevant research results are reported and reported truthfully and honestly with no bias or influence from funding sources, regardless of positive or negative findings. 